\section{Korrespondenzadresse}

\section{Sonja Kulschewski}

Schleswig-Holsteinische Krebsgesellschaft e.V. Alter Markt 1-2, 24103 Kiel, Deutschland

info@krebsgesellschaft-sh.de

Forum $2021 \cdot 36: 264$

https://doi.org/10.1007/s12312-021-00925-0

Online publiziert: 24. März 2021

(c) Springer Medizin Verlag $\mathrm{GmbH}$, ein Teil von

Springer Nature 2021

a)

SÄCHSISCHE KREBSGESELLSCHAFT E.V.

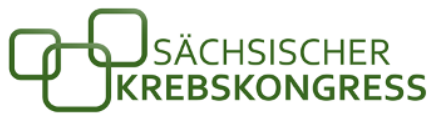

Sächsische Krebsgesellschaft e.V.

Zwickau, Deutschland

\title{
12. Sächsischer Krebskongress
}

Für den September 2021 plant die Sächsische Krebsgesellschaft e. V. die Durchführung des 12. Sächsischen Krebskongresses in Chemnitz. Es handelt sich dabei um einen Nachholtermin der ursprünglich für den April geplanten Expertentagung.

Der Kongress steht in diesem Jahr unter dem Motto „Prävention. Ernährung. Immunologie " und trägt damit umfassend dem Thema der Vorbeugung von Krebserkrankungen Rechnung. So können konkrete präventive Maßnahmen, wie Rauchverzicht, nach Studienlage bis zu $85 \%$ der Neuerkrankungen an Lungenkrebs verhindern. Im zweiten Thema „Ernährung“ wollen die Veranstalter deren spezielles Präventionspotenzial von $30 \%$ über alle Krebsarten verteilt anhand von neueren Forschungsergebnissen beleuchten und mit praktischen Anwendungen verdeutlichen. Letztlich soll im Rahmen des Kongresses auch dem Immunsystem, dem zentralen Adressat präventiver Strategien, Aufmerksamkeit geschenkt werden.

Beim Sächsischen Krebskongress finden sich Mediziner aus dem Bereich der onkologischen Versorgung zusammen, um aktuelle Strategien der Onkologie zu diskutieren, ebenso wie das an der Ver- sorgung onkologischer Patienten beteiligte Fach- und Assistenzpersonal.

Die Durchführung des Kongresses ist am 18.09.2021 im zentralen Hörsaalgebäude der Technischen Universität Chemnitz vorgesehen. Sollte es die Corona-Pandemie erfordern, planen die Veranstalter zusätzlich eine Ausweitung auf den Online-Bereich.

Programm und Informationen: www. skk2021.de

\section{Korrespondenzadresse}

Sächsische Krebsgesellschaft e.V.

Haus der Vereine

Schlobigplatz 23, 08056 Zwickau, Deutschland info@skg-ev.de 